\title{
IMPACTO DAS VARIÁVEIS DE USO E OCUPAÇÃO DO SOLO NA DEGRADAÇÃO DA QUALIDADE DA ÁGUA NA BACIA HIDROGRÁFICA DO RIO ARUJÁ (SÃO JOSÉ DOS PINHAIS - PR)
}

\author{
Impact of the Use and Soil Occupation Variables in the Water \\ Quality Degradation in Aruja River Hydrographic Basin (São \\ José dos Pinhais - PR)
}

\author{
Renato Cabral Bossle \\ Marcelo Antunes Nolasco ${ }^{2}$
}

\section{Resumo}

O presente trabalho apresenta as variações ocasionadas pelos impactos ambientais sofridos pelo rio Arujá no intervalo entre os anos de 1999 a 2005 mediante a utilização de fotos aéreas (1999), de satélite (2004) e das obtidas por uso de máquina fotográfica (2005). Uma análise comparativa das imagens mostra as mudanças ocorridas no meio físico da bacia do Rio Arujá e suas implicações no ecossistema local. Pelo fato do rio Arujá ser afluente do rio Miringuava, o qual faz parte dos mananciais de abastecimento da Região Metropolitana de Curitiba, ele pode ser utilizado como um mecanismo de alerta. Ao final, é proposta uma série de medidas mitigadoras de impacto ambiental.

Palavras-chave: Bacia hidrográfica; Rio Arujá; Qualidade de águas; Poluição ambiental.

\section{Abstract}

The present paper shows the occasional variations caused by the environmental impacts suffered by Aruja River between the years of 1999 and 2005, through the use of aerial photos (1999), satellite pictures (2004) and the ones taken by a digital camera (2005). A comparative analysis of the images shows the changes that happened with physical environment at Aruja River Basin and its implications in the local ecosystem. Because of the fact that Aruja River is a Miringuava River affluent, which is part of the water supply complex of Curitiba Metropolitan Region, it can be used as an alert mechanism. At the end, there have been made several suggestions of steps in order to mitigate the environmental impacts.

Keywords: Hydrographic basin; Aruja River; Water quality; Environmental pollution.

1 Biólogo, Pós-Graduado em Gestão dos Recursos Naturais pela PUCPR. Técnico da Secretaria do Meio Ambiente da Prefeitura Municipal de São José dos Pinhais - PR.

2 Biólogo, Dr. Professor da Pontifícia Universidade Católica do Paraná. Professor do Programa de Pós-Graduação em Engenharia de Recursos Hídricos em Ambiental da Universidade Federal do Paraná.

E-mail: mnolasc@terra.com.br. 


\section{Introdução}

A partir da segunda guerra mundial, São José dos Pinhais se beneficiou do setor madeireiro, que compensou a estagnação da economia ervateira. Em 1955, o ramo madeireiro representava $42 \%$ do valor total da produção, seguido pelos produtos alimentares, com 34\%.

O Município, desde o início da década de trinta, sediava a maior usina hidrelétrica do Paraná, a Usina de Chaminé, construída para abastecer os municípios de Curitiba, Piraquara, Campo Largo e São José dos Pinhais. Na década de quarenta, com a expansão da aviação civil no Brasil, escolheu-se a região de Curitiba para a instalação de base aérea e pistas de pouso com tecnologia americana. Essa base foi construída em área da Colônia Afonso Pena, muito próxima à cidade de São José dos Pinhais. Nos anos 40 Curitiba se configurava como um centro de convergência e de distribuição de grande parte da produção econômica do Estado. Entre 1940 e 1950, enquanto a população curitibana cresceu $41,87 \%$, o conjunto dos municípios vizinhos apresentou um crescimento de $13,82 \%$. Nesse período, os núcleos urbanos da região apresentavam-se bastante distantes do tecido urbano de Curitiba.

Em meados da década de 60, a malha urbana de Curitiba ultrapassou a BR-116 em direção leste, formando um forte vetor de ligação entre São José dos Pinhais e a ocupação da baixada do vale do Rio Iguaçu. Nesse período, o governo paranaense investiu em infra-estrutura, com a pavimentação das rodovias BR-116 e BR-376, e, posteriormente, com a construção da BR-277, colocando São José dos Pinhais em posição privilegiada com relação a um entroncamento viário de importância nacional.

Na década de 70, a BR-116 ficou totalmente inserida no tecido urbano de Curitiba e o próximo umbral leste passou a ser a estrada de ferro junto à várzea do Rio Iguaçu. O município de São José dos Pinhais consolida faixas urbanizadas com Curitiba. Essa conurbação de Curitiba com as cidades vizinhas foi oficialmente reconhecida em 1971, quando a legislação nacional incluiu Curitiba entre as nove regiões metropolitanas do Brasil. Isso resultou na integração oficial de São José dos Pinhais a um centro dinâmico, cujo pólo é Curitiba. Do ponto de vista funcional, o papel de São José dos Pinhais altera-se, passando de um município com funções comerciais (entreposto do seu meio rural e outros centros urbanos) e cidade "dormitório" para a mão-de-obra de Curitiba, a uma cidade industrial, sem perder totalmente as duas funções anteriores.

\section{Uso e ocupação do solo na bacia do Rio Arujá}

É provável que os primórdios da ocupação da área que abrange a bacia do Rio Arujá tenham sido caracterizados pelo desmatamento de Floresta Ombrófila Mista, típica da região, para aproveitamento de madeira, principalmente de araucária (Araucaria angustifolia) e de outras essências de interesse econômico, como a canela e a imbuia. A julgar pelo uso atual do solo na bacia e pelo histórico do município, o local teve, durante décadas, uma aptidão tipicamente agrícola, caracterizada pelo cultivo diversificado de hortícolas e frutíferas.

Atualmente a bacia do Rio Arujá conta com cerca de 62 empresas, catalogadas junto ao Município, de acordo com o Catálogo das Indústrias de São José dos Pinhais - Edição 2004 (SICTUR, 2004). A classificação e quantificação dessas empresas podem ser acompanhadas na tabela seguinte. 
TABELA 01 - Qualificação e quantificação da atividade industrial na Bacia do Rio Arujá. Table 01 - Industrial activity qualification and quantification in the Aruja River Basin.

SETOR INDUSTRIAL

SUB-SETOR INDUSTRIAL

QUANTIDADE

DE EMPRESAS

Indústria de transformação

Fabricação de móveis com predomínio de madeira

11

Fabricação de vidro plano e de segurança

1

Fabricação de rações balanceadas para animais

2

Fabricação de artefatos de gesso e estuque

1

Têmpera, cementação e tratamento térmico do aço; usinagem, galvanotécnica e solda

Fabricação de fios, cabos e condutores elétricos isolados 1

Fabricação de produtos de laticínio 1

Fabricação de artefatos de plástico para outros usos 1

Fabricação de outras máquinas e equipamentos de uso específico 1

Fabricação de artefatos em pedras e/ou fibra de vidro 2

Fabricação de cabines, carrocerias e reboques para caminhão 1

Frigorífico com abate de suínos e/ou preparação de carne e subprodutos 1

Fabricação de outras máquinas e equipamentos de uso geral 1

Fundição - Fabricação de peças fundidas de ferro e aço 2

Fabricação de outros produtos alimentícios 1

Fabricação de artefatos de cimento para uso na construção civil 3

Fabricação de esquadrias de madeira 2

Fabricação de peças e acessórios de metal para indústria automobilística 2

Fabricação de outros produtos elaborados de metal 2

Fabricação de artefatos diversos de madeira - exclusive móveis 4

Fabricação de biscoitos e bolachas 1

Fabricação de esquadrias de metais 2

Fábrica de equipamentos para distribuição e controle de energia elétrica 1

Fabricação de produtos de padaria, confeitaria e pastelaria 1

Fabricação de máquinas e equipamentos para agricultura, avicultura e obtenção de produtos animais

Fabricação de outros artigos têxteis - exclusive vestuário 1

Fabricação de produtos de fumo 1

Fabricação de artefatos têxteis a partir de tecidos 2

Desdobramento de madeira 1

Fabricação de artefatos estampados de metal 1

Fabricação de artefatos de cerâmica ou barro cozido para uso na construção civil 1

Fabricação de artefatos diversos de plástico 1

Fabricação de fitas adesivas e formulários contínuos com ou sem impressão 1

Fabricação de material plástico para uso na construção civil 1

Fabricação de laminados de madeira $\quad 1$

Fabricação de peças fundidas de metais não-ferrosos e suas ligas 1

Fabricação de artefatos diversos de borracha 1

Total

Fonte: SICTUR, 2004 
Como se pode constatar na tabela, há um predomínio de indústrias que utilizam a madeira como matéria-prima. Do total de 62 empresas, 19 $(30,6 \%)$ pertencem a subsetores industriais que utilizam esse tipo de material. Outro grupo de relevância na área da bacia é o que utiliza metais ferrosos ou não-ferrosos como matéria-prima: das 62 empresas, $16(25,8 \%)$ se enquadram em um ou outro subsetor afim.

Embora bastante diversificada, a atividade industrial não é a predominante na área de abrangência da bacia. Verifica-se, mediante o uso de imagem de satélite recente (IDU, 2004), que existem grandes áreas na bacia ocupadas por terras utilizadas para atividades agrícolas, outras para a criação de animais, destacando-se a piscicultura, e uma pequena parcela destinada a moradias. Fato interessante a salientar é que, mesmo com a pressão de ocupação sofrida pelo município nos últimos anos, a bacia mostra algumas manchas de área verde de tamanhos variados, porém expressivos (FIGURA 1).

\section{FIGURA 1 - Diversificação de atividades e reflexos na estrutura física do meio ambiente na bacia do rio Arujá.}

Figure 1 - Activities diversification and consequences in the environment physical structure throughout the Aruja River basin.

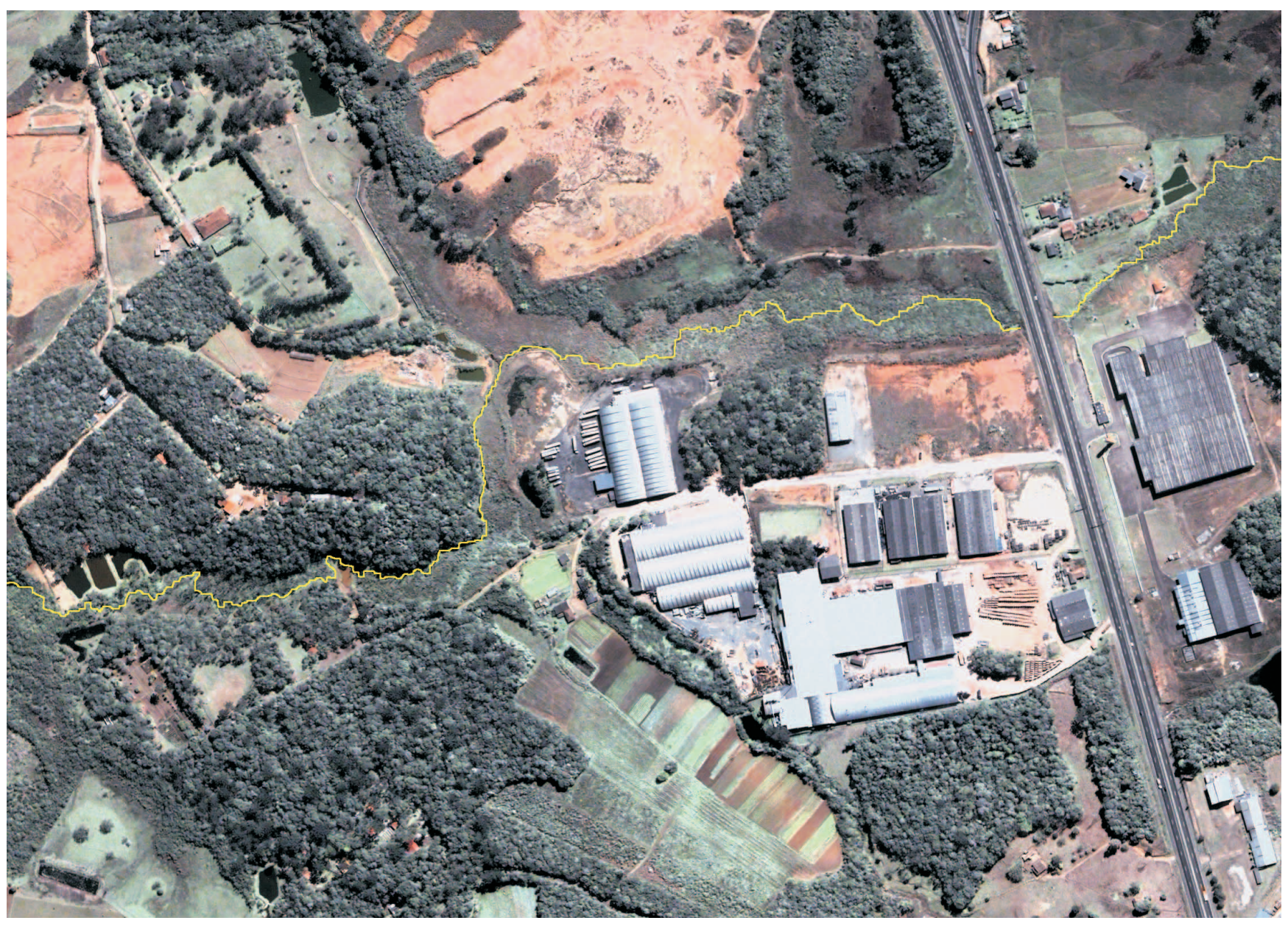

Fonte: Instituto de Desenvolvimento Urbano - IDU, 2004 
De acordo com dados obtidos no Mapa 2 do Anexo II da Lei Complementar $n^{\circ} 16$, de 11 de novembro de 2005, a área de abrangência da bacia do rio Arujá apresenta cinco zonas referenciadas como ZR-4 (Zona Residencial 4), ZR-2 (Zona Residencial 2), ZIS (Zona Industrial e de Serviços), ZRE-2 (Zona Residencial Especial 1) e ZRE-2 (Zona Residencial Especial 2). (IDU, 2005)

Essas zonas, de acordo com a referida Lei, podem abrigar desde habitações unifamiliares até indústrias de grande porte, com os usos variando entre adequados e permissíveis de acordo com as vias onde pretendem ser instaladas essas edificações. Nos Anexos 4 e 5 são mostrados o mapa do zoneamento na área de abrangência da bacia, as tabelas que mostram as possibilidades de uso e ocupação do solo nas respectivas zonas, bem como as tabelas de qualificação dos usos permitidos e permissíveis em cada uma das zonas. A Figura 2 a seguir mostra o zoneamento na região da bacia do Rio Arujá.

FIGURA 2 - Zoneamento de uso e ocupação do solo na área de abrangência da bacia do Rio Arujá. Figure 2 -Zoning of the use and soil occupation in the domain of the Aruja River basin area.

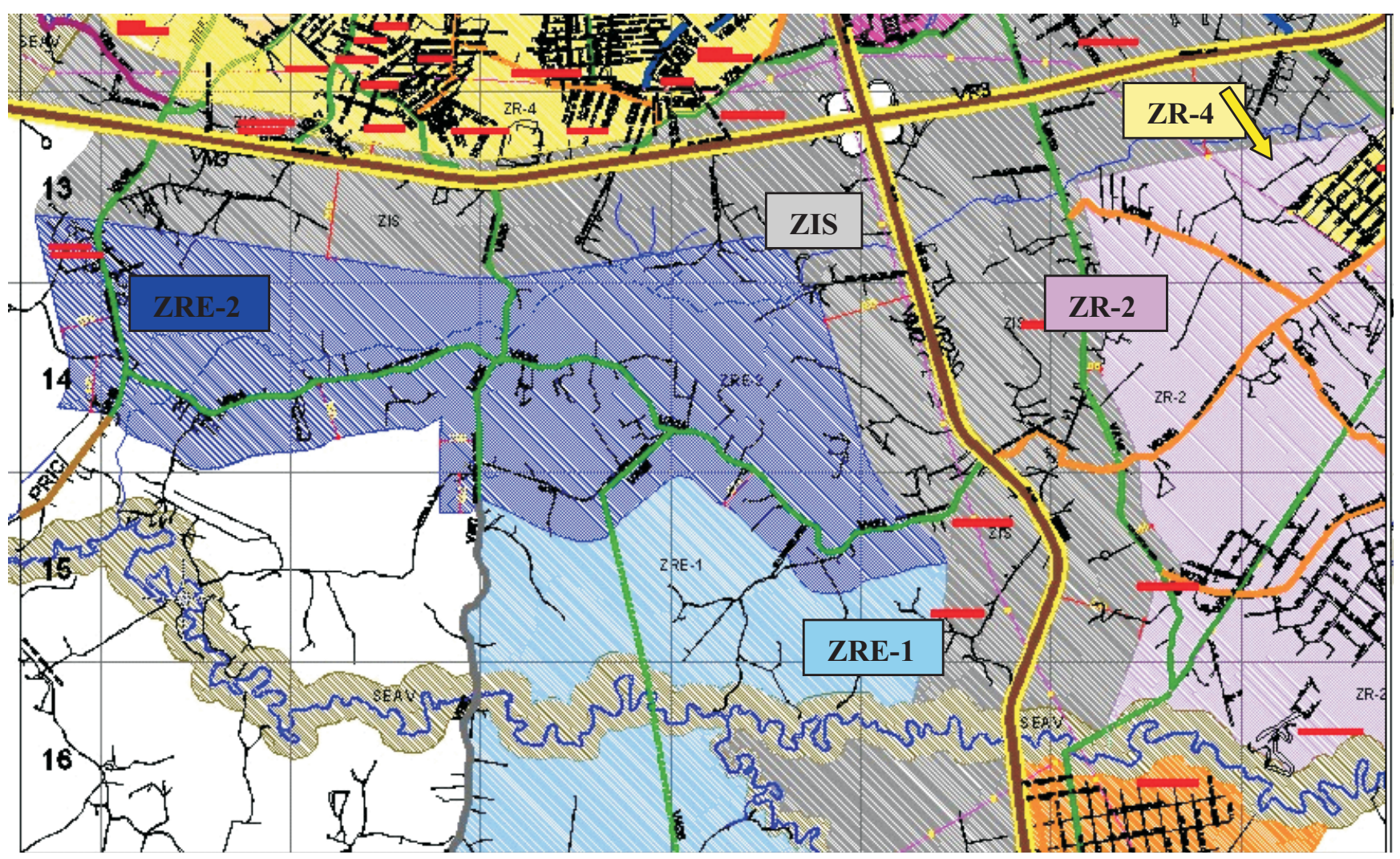

Fonte: IDU, 2005. (modificado)

\section{Análise comparativa entre 1999 a 2005}

\section{Metodologia}

Para a realização dessa análise comparativa foram utilizados mapas de fotos aéreas e mapa de satélite de alta resolução Quickbird II, além de visitas a campo para verificar as condições atuais e realizar o registro fotográfico.

Os mapas de fotos aéreas foram obtidos na Secretaria Municipal de Urbanismo da Prefeitura
Municipal de São José dos Pinhais e apresentam dados relativos ao ano de 1999. Para compor a imagem utilizada para a análise, várias fotos foram sobrepostas com a utilização de software gráfico apropriado.

O mapa de satélite foi obtido junto ao IDU Instituto de Desenvolvimento Urbano, uma autarquia vinculada à Prefeitura Municipal de São José dos Pinhais. A imagem foi obtida a partir de satélite de alta resolução Quickbird II na data de 6 de julho de 2004. A resolução espacial da imagem é de $0,60 \mathrm{~m}$. Outros dados relevantes sobre a imagem: 
Resolução Radiométrica: 4 Bandas espectrais

Sistema de Projeção: $\quad$ Projeção: UTM, Zona 22 SUL [Metros]

Datum: SAD-69/Brasil

Coordenadas: Canto superior esquerdo: Geográfica:

S: $25^{\circ} 34^{\prime} 03.80^{\prime \prime} \mathrm{O}: 49^{\circ} 13^{\prime} 45.53^{\prime \prime}$

UTM: L:677868.054 S:7170990.590

Canto inferior direito: Geográfica:

S:2535'20.86" O:4909'19.21"

UTM: L:685267.997 S:7168518.255
No trabalho em campo foi utilizada máquina fotográfica Sony DSC-P92 para a obtenção de fotos digitais. Todas as fotos presentes neste trabalho apresentam resolução de 1.2 pixels (1280 x 960 pixels), cor de 24 bits e foram obtidas em dia claro, com luz natural. A coleta dos dados, portanto, é oriunda dos mapas disponíveis, com intervalo aproximado de 5 anos entre uma imagem e a outra (1999 e 2004), e das fotografias obtidas em campo. Essas últimas permitem verificar mudanças ocorridas a partir de 6 de julho de 2004, uma vez que a imagem de satélite, que é a mais recente das duas imagens disponíveis, foi obtida nessa data.

\section{FIGURA 3 - Área das nascentes do rio Arujá - 1999.}

Figure 3 - Aruja River springs Area - 1999.

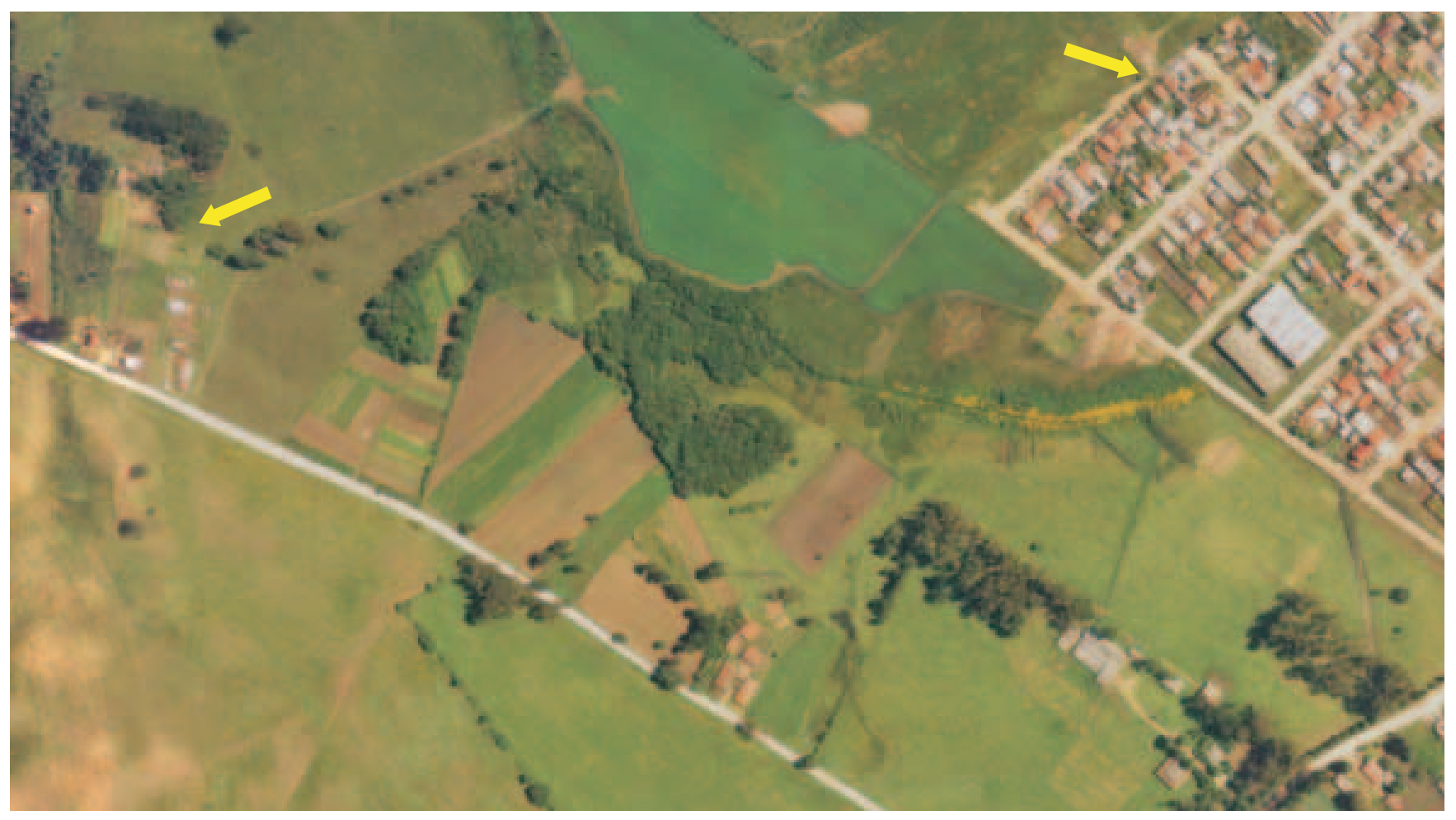

Fonte: SEMU, 1999.

\section{Análise e interpretação dos dados}

Observando-se rapidamente as duas imagens, pode-se constatar que ocorreram pequenas transformações na paisagem. Essa interpretação visual, entretanto, pode esconder inúmeras mudanças de pequeno porte que, muitas vezes, podem ter alcance extraordinário quando se trata de uma análise de impactos no meio ambiente.
Com a finalidade de facilitar a análise comparativa foram selecionadas secções similares, obtidas a partir das duas imagens, das áreas onde foram verificadas mudanças na composição da paisagem. Essas secções foram colocadas em seqüência para uma melhor comparação do efeito ocasionado. As mudanças após a data de 6 de julho de 2004 foram constatadas com fotos digitais recentes e, portanto, sem a visão aérea. 
FIGURA 4 - Área das nascentes do rio Arujá - 2004.

Figure 4 - Area of the Aruja River water sources - 2004.

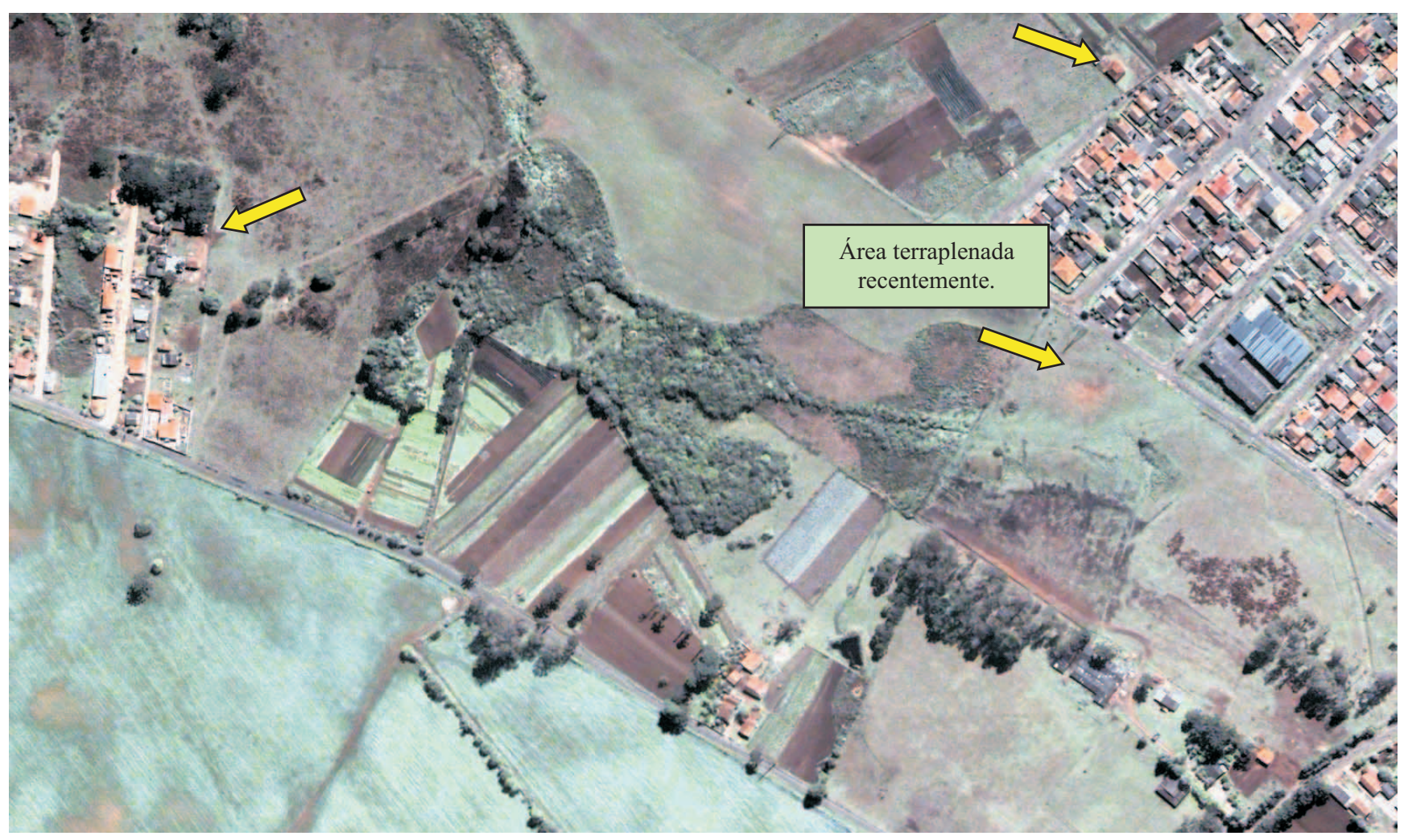

Fonte: IDU, 2004.

Como pode ser observado nas Figuras 5 e 6, o adensamento populacional no Jardim San Francisco e o surgimento de novas unidades habitacionais à jusante indicam uma maior carga de efluentes a ser lançada diariamente sobre o rio. A região não é servida por rede de destinação e tratamento de esgotos domissanitários. Conforme constatado em campo, junto à nascente situada no
Jardim San Francisco, há uma rede de tubulação para águas pluviais que, além de canalizar a água proveniente dessa nascente, recebe os efluentes domésticos e os encaminha ao rio, sem qualquer forma de tratamento prévio (FIGURA 6). Na mesma figura pode ser observada uma parte da área terraplenada recentemente, a qual não é mostrada nas imagens aéreas. 


\section{FIGURA 5 - Canalização de águas provenientes da nascente e de chuvas, junto com efluentes domissanitários}

Figure 5-Rain and water canalization proceeding from the water source, with effluentsanitary water.

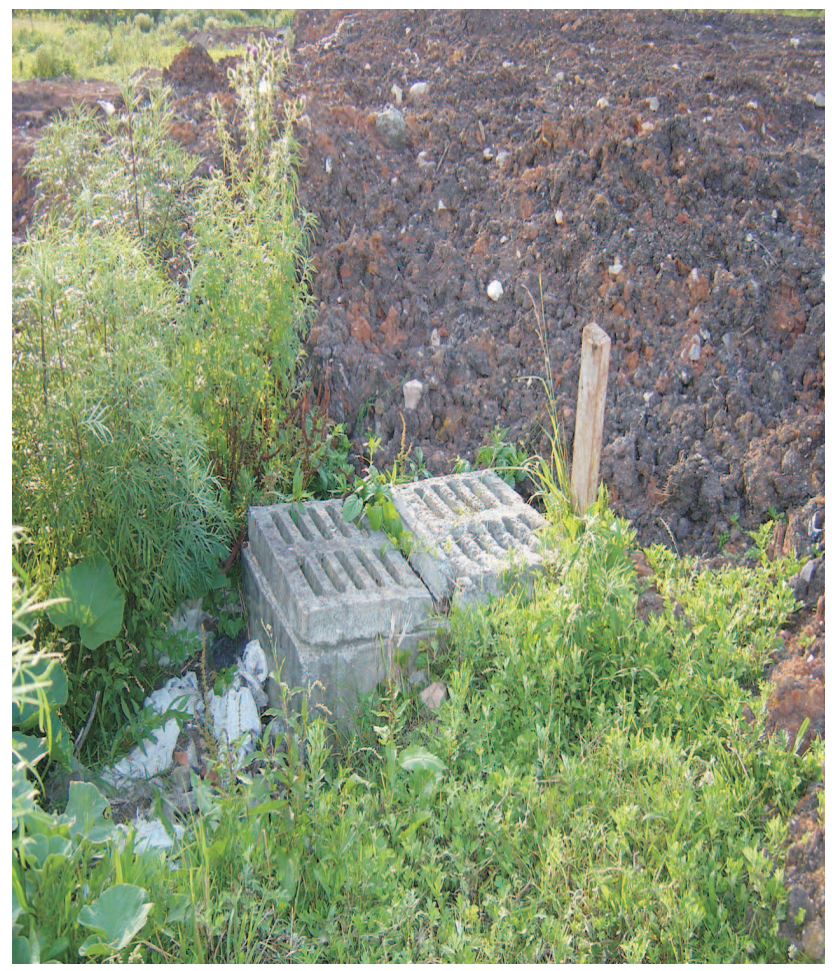

\section{FIGURA 6 - Terraplenagem em área próxima ao Jardim San Francisco.}

Figure 6-Leveling of the ground next to the San Francisco Garden area.

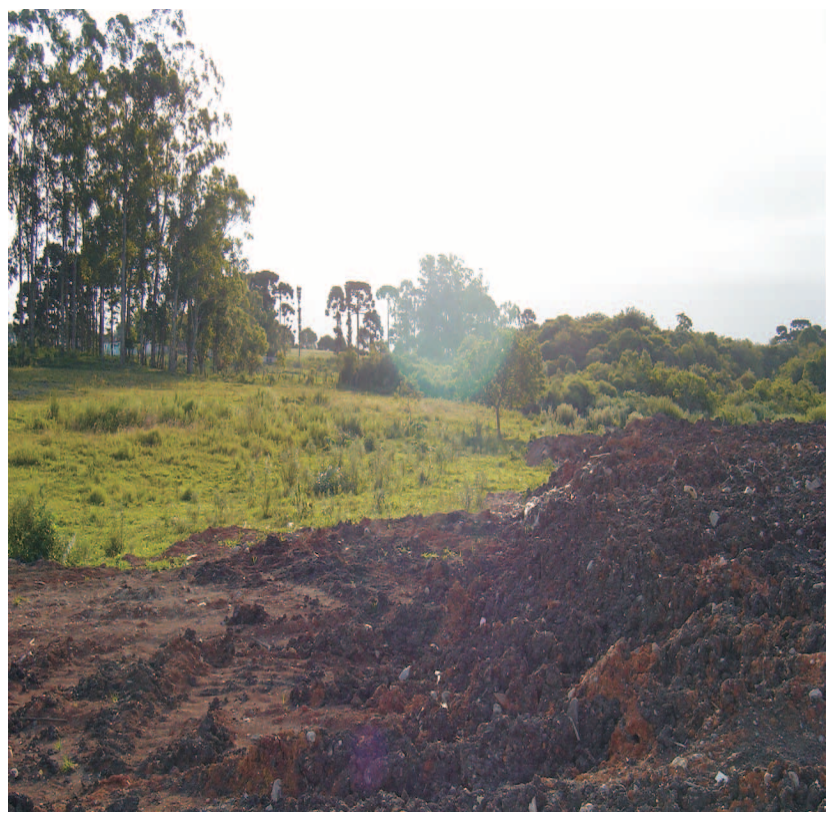

Fonte: Foto do Autor Fonte: Foto do Autor
Do ponto de vista dos impactos ambientais ocasionados nesta secção da bacia, a conjugação dos eventos canalização da nascente e despejo de efluentes domissanitários é o que se apresenta mais grave. O Rio Arujá está sofrendo o mais comum e o pior tipo de degradação ambiental reservado aos corpos hídricos: a poluição por despejos de efluentes domésticos já na sua origem, a nascente. Conforme será mostrado adiante, esse fato leva a uma descaracterização do recurso de tal forma que a vida aquática passa a ser a maior prejudicada. De acordo com Andreoli (2003), na área urbana, o grande crescimento, acompanhado pela ocupação inapropriada dos mananciais, contribui para alteração do regime hídrico e a redução da qualidade das águas. Na seqüência, o uso agrícola das águas passa a ser fortemente prejudicado, uma vez que as elevadas concentrações de coliformes fecais e outros agentes patogênicos comprometem significativamente a qualidade do recurso. Na visita realizada nessas áreas ficou evidente a conscientização do agricultor na busca de águas de qualidade desejável. Restou, ainda, o relato das condições do ambiente natural de outrora, antes das influências negativas da ação antrópica no local.

Importante é considerar também que a região deve certamente ter sofrido desmatamento para dar espaço ao cultivo agrícola, fato esse que, sabidamente, é prejudicial à integridade da nascente. A Lei Federal $n^{\circ} 4.771$ de 15 de setembro de 1995, em seu Artigo $2^{\circ}$, alínea "c", especifica que se consideram de preservação permanente, pelo só efeito desta Lei, as florestas e demais formas de vegetação natural situadas: nas nascentes, ainda que intermitentes e nos chamados "olhos d'água", qualquer que seja a sua situação topográfica, num raio mínimo de 50 (cinqüenta) metros de largura.

Ao que pode ser facilmente constatado nas imagens, a nascente principal do Arroio Arujá e a nascente situada no Jardim San Francisco estão sofrendo pelo descumprimento da legislação vigente. Essa última sofre um crime ainda mais grave: está, infelizmente, sendo poluída diretamente pelo despejo de esgoto doméstico. O efeito dessa poluição é observado à jusante no rio, conforme figura a seguir. 
FIGURA 7 - Impacto ocasionado pelo despejo de efluentes domésticos, oriundos do Jd. San Francisco, no Rio Arujá.

Figure 7 - Impact caused by domestic effluents, from San Francisco Garden, in the Aruja river

Na secção imediatamente seguinte a essa, retratadas nas figuras 8 e 9, observa-se o surgimento de mais edificações residenciais e de um condomínio industrial, o qual já foi alvo de denúncias estampadas nos meios de comunicação local e estadual. A matéria da primeira página do Jornal São José dos Pinhais Metrópole, edição $n^{\circ}$ 162, de 10 de junho de 2004, mostra a agressão ambiental sofrida pelo recurso com a construção de um muro junto a sua margem e com a conse-

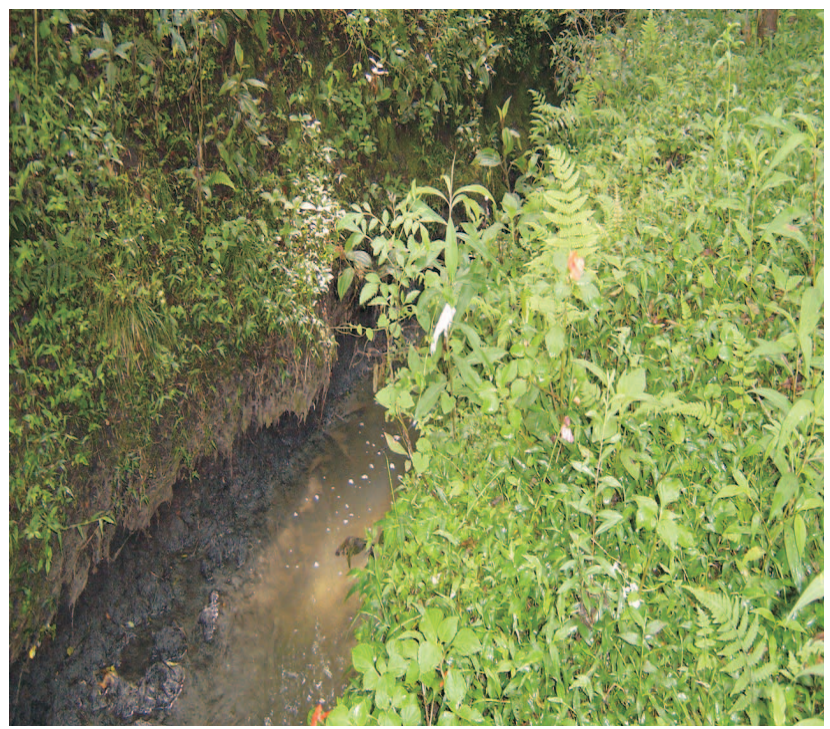
qüente destruição da mata ciliar.

FIGURA 8 - Situação da bacia em área à jusante e próxima à cabeceira - 1999.

Figure 8 - Basin situation in the downstream and next to beadwater area - 1999.

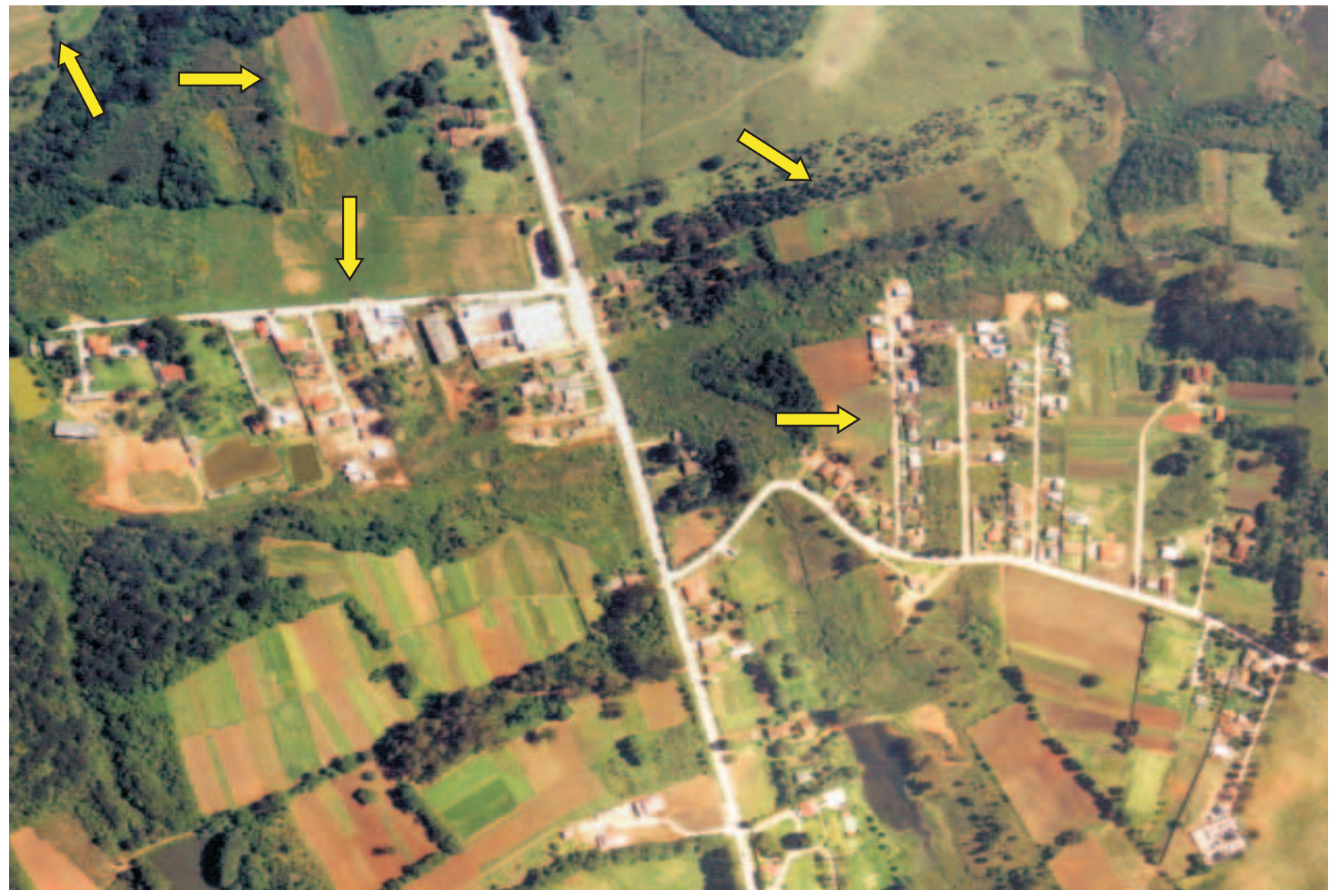

Fonte: SEMU, 1999. 
FIGURA 9 - Situação da bacia em área à jusante e próxima à cabeceira - 2004.

Figure 9-Basin situation in the downstream and next to beadwater area-2004.

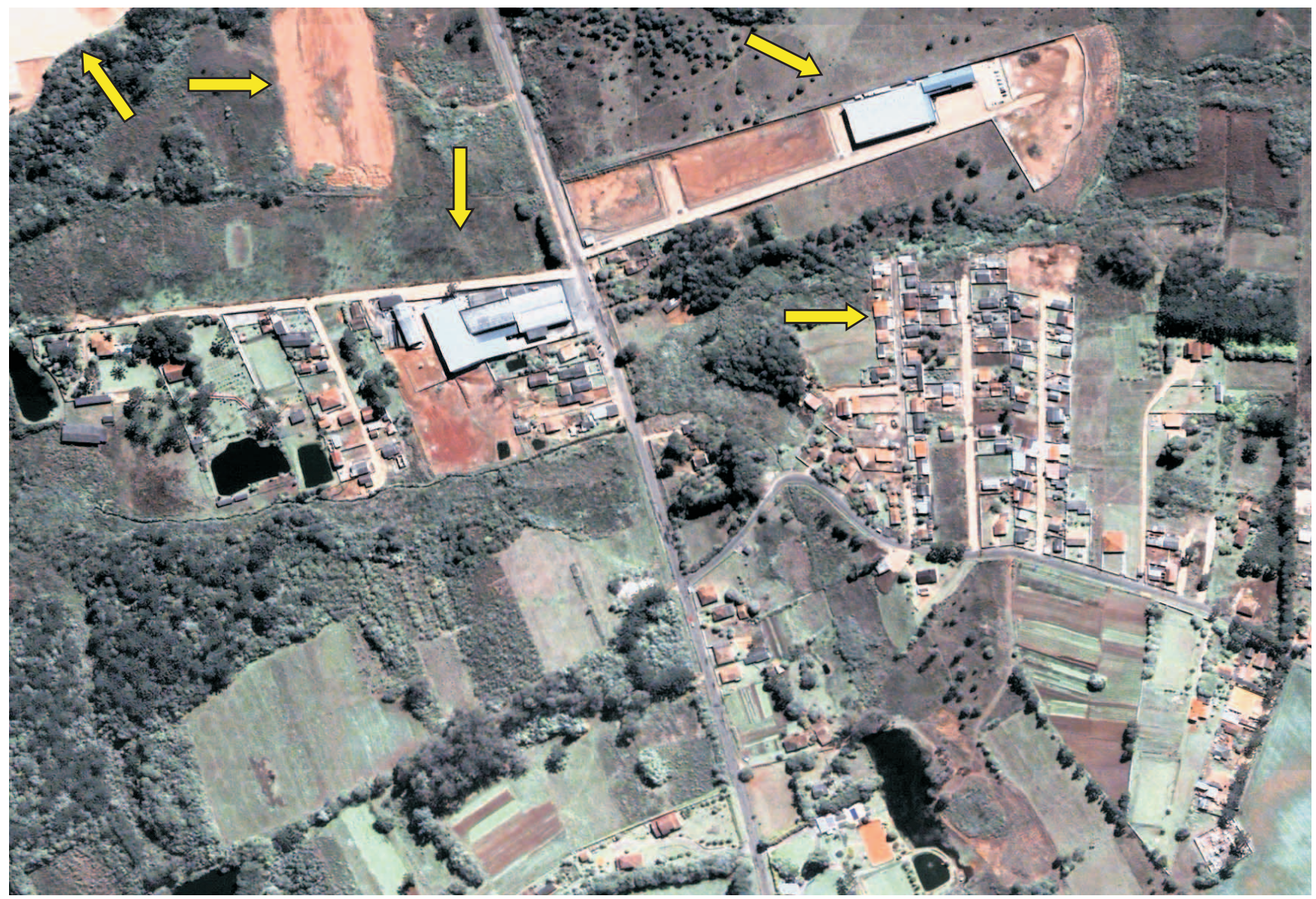

Fonte: IDU, 2004.

Nessa secção da bacia podem ser observadas uma série de ações que certamente resultam em danos ambientais: construções avançando em área de preservação permanente (condomínio industrial), aumento na densidade demográfica com o incremento de novas moradias e o conseqüente aumento do lançamento de efluentes domésticos, ações de terraplenagem, resultantes das obras do Contorno Leste (BR-116), com o inevitável acúmulo de sedimentos no leito do rio e o seu assoreamento, e, como pode ser observado, ainda que não tenha sido apontado por setas, a pavimentação das estradas que ocasionam, pela impermeabilização provocada, redução na infiltração de água no solo.

Um outro fato relevante a ser considerado e que certamente tem influência nas condições ambientais da bacia do Arroio Arujá refere-se à construção da Rodovia Contorno Leste, um prolongamento da Rodovia Federal BR-116. Essa obra, durante sua execução, foi responsável por uma série de situações problema ao nível ambiental: aterros, remoções de terra em grande quantidade, canalizações, drenagens, remoção de vegetação e mudanças na fisionomia do meio ambiente em geral. Entretanto, a maior contribuição negativa dessa obra sobre a bacia só começa a aparecer após sua conclusão: o estabelecimento de novas indústrias ao longo de seu trajeto e a conseqüente possibilidade de poluição do recurso pelo despejo irregular ou acidental de efluentes industriais. As mudanças ocasionadas por essa obra serão citadas em outras comparações de imagens, tal como apresentadas nas Figuras 8 e 9.

Continuando a seguir em direção à foz do Rio Arujá novas situações são encontradas. Na área que abrange o entroncamento da Rodovia Federal BR-376 com a BR-116 (Contorno Leste) podem ser observadas outras cenas de interesse para a análise de impactos ambientais, conforme ilustrado nas Figuras 10 e 11. 
FIGURA 10: Situação da bacia nas proximidades do entroncamento da BR-376 com o Contorno Leste- 1999.

Figure 10: Basin situation in the neighborboods of the crossing between BR-376 with East Contour road - 1999.

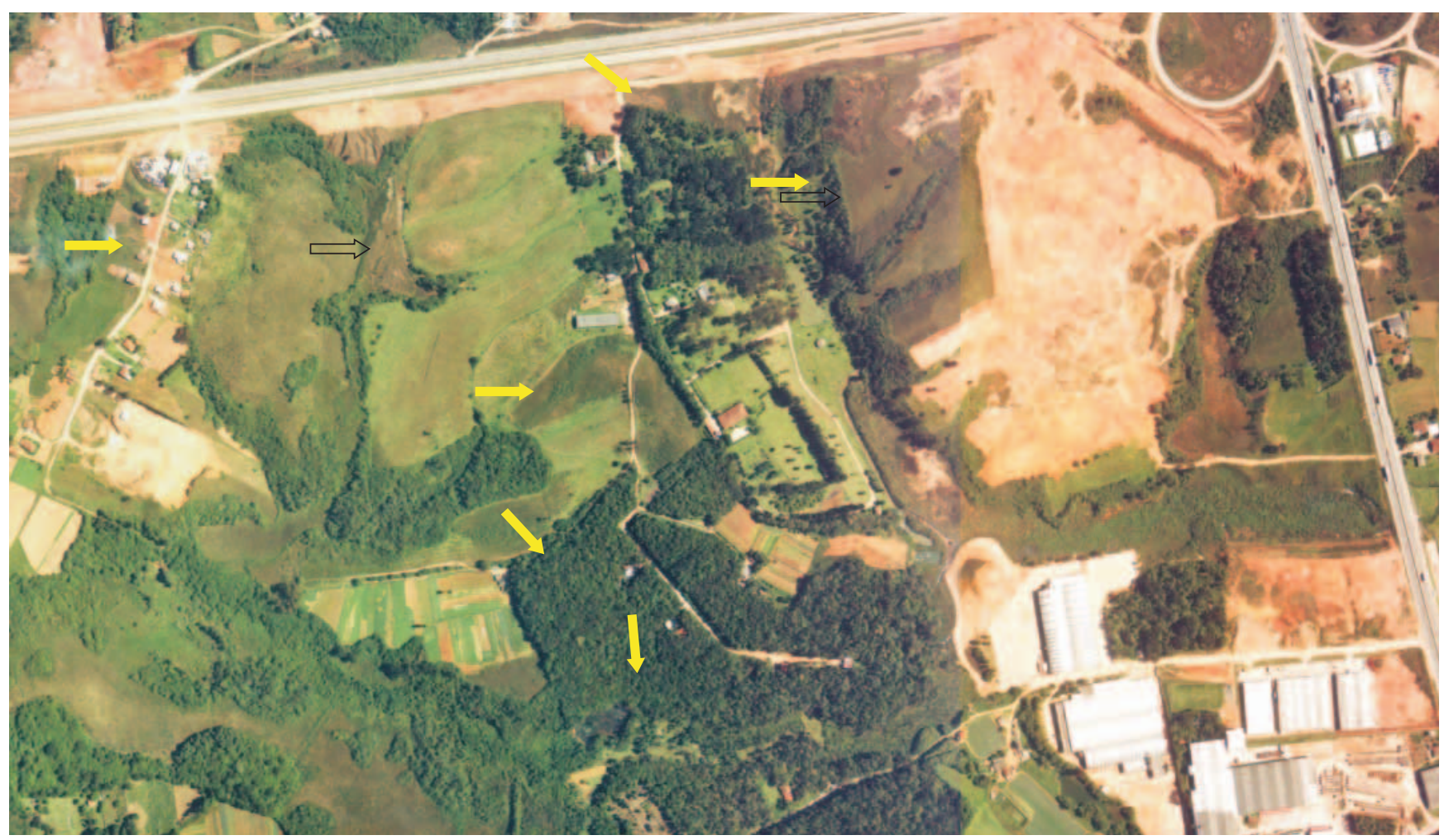

Fonte: SEMU, 1999.

FIGURA 11: Situação da bacia nas proximidades do entroncamento da BR-376 com o Contorno Leste- 2004.

Figure 11: Basin situation in the neighborhoods of the crossing between BR-376 with East Contour road - 2004.

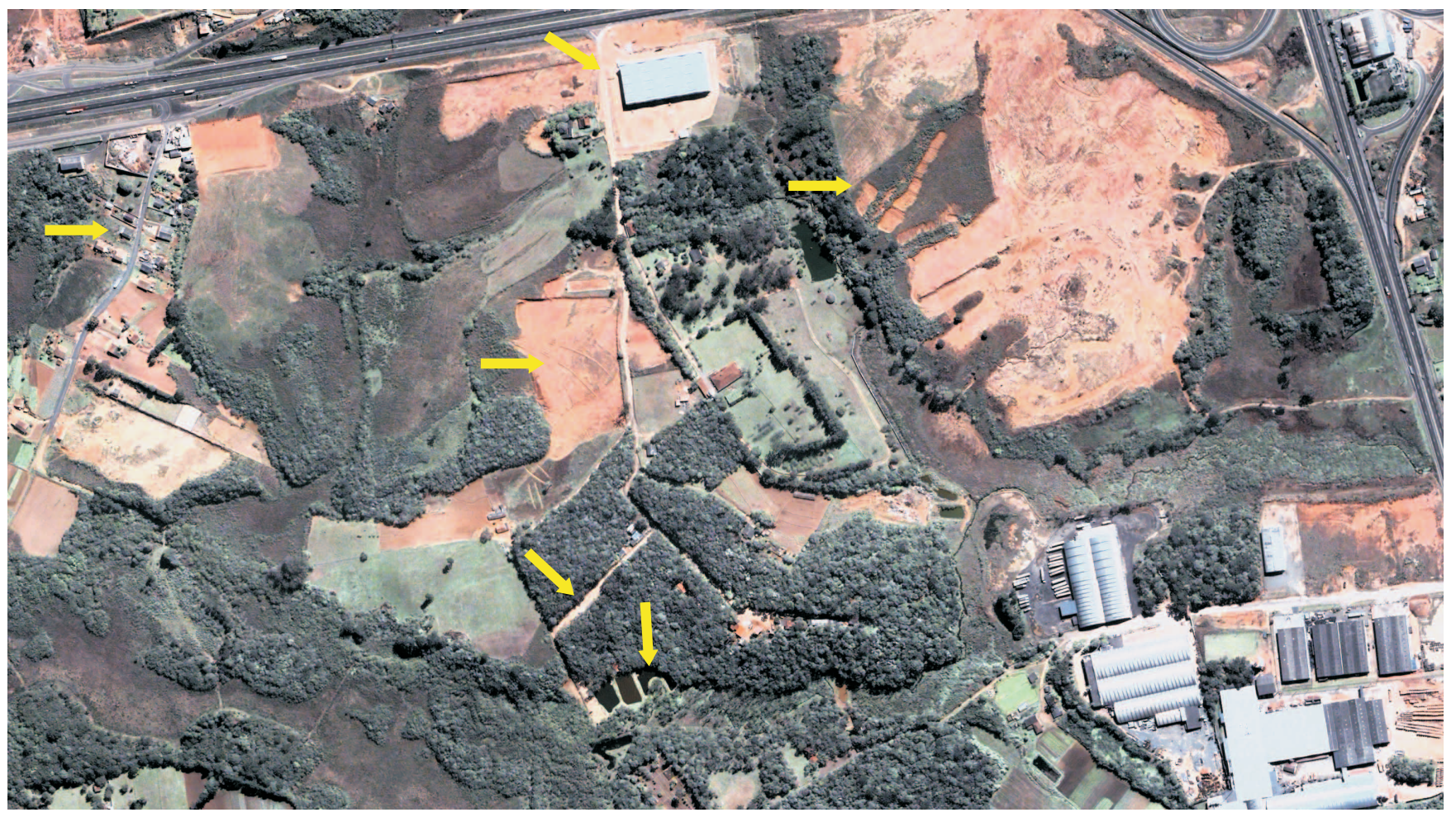

Fonte: IDU, 2004. 
Novamente as cenas se repetem com terraplenagens, aumento de edificações residenciais, construção de novas indústrias e um fato novo no cenário: a remoção de mata ciliar para a construção de tanques de piscicultura e de estradas para seu acesso. É sabido que as atividades de criação de animais podem causar impactos ao meio ambiente se não forem devidamente conduzidas. Nesse caso, a criação em si não é tão relevante quanto os meios que foram utilizados para a sua implantação. Nesse contexto, a ação da população com denúncias em órgãos de fiscalização ambiental e uma ação mais concisa desses mesmos órgãos podem conduzir a resultados menos impactantes e mais satisfatórios ao meio ambiente, ainda que essa atividade, dentre todas as já citadas, seja a de menor impacto ambiental.

Ao longo do percurso, após essa secção da bacia, encontram-se modificações menores e já relatadas, principalmente no que diz respeito à impermeabilização de estradas com pavimentação asfáltica e construção de novas unidades habitacionais. Algumas indústrias de pequeno porte podem ter sido construídas nesse trajeto. Naturalmente que todas essas "modificações menores", como já citado, podem trazer impactos ambientais muito grandes. Tudo depende da natureza do empreendimento e da fiscalização dos órgãos ambientais envolvidos.

\section{Proposição de medidas mitigadoras para os impactos identificados}

De posse do conhecimento sobre os danos atuais vividos pelo meio físico e sofridos por toda a comunidade biótica da área de abrangência da bacia do Rio Arujá, algumas medidas podem e devem ser adotadas a fim de minimizar ou mesmo cessar os impactos ambientais. Essas medidas mitigadoras são listadas a seguir.

1. Coleta e destinação adequada dos efluentes domésticos de todas as residências alocadas na área da bacia hidrográfica: essa atribuição é da Companhia de Saneamento do Paraná - SANEPAR e está prevista em contrato estabelecido entre a Prefeitura Municipal de São José dos Pinhais e a referida prestadora de serviços.

2. Criação de um comitê de gestão da bacia, conforme preconizado na Lei Estadual $\mathrm{n}^{\circ}$ 12.726, de 26 de novembro de 1999: esse comitê gestor é formado por membros representativos de toda a comunidade civil.

3. Criação de um mapa da bacia contendo todos os afluentes do Rio Arujá e identificando todas as indústrias presentes e suas atividades, bem como as propriedades agrícolas e outras atividades de interesse ambiental: esse mapa pode ser desenvolvido pela equipe técnica da Prefeitura Municipal de São José dos Pinhais, sempre com assessoramento da equipe de técnicos da Secretaria de Meio Ambiente do Município.

4. Sinalização "in loco" das nascentes do rio conforme citado na Lei Municipal $n^{\circ} 175$ de 14 de maio de 2001, além da colocação de outras placas indicativas da presença do rio ao longo das Rodovias Federais BR-116 (Contorno Leste) e BR376: essa atividade pode ser desenvolvida pela Prefeitura Municipal de São José dos Pinhais, com auxílio técnico da Secretaria de Meio Ambiente do Município.

5. Criação de um Programa de Educação Ambiental no Município que vise dar subsídios para toda a comunidade local da bacia, enfatizando a necessidade de preservação das nascentes, da mata ciliar e dos cuidados necessários na destinação final dos efluentes: essa atividade deve ser idealizada e realizada por técnicos devidamente habilitados da Secretaria Municipal de Meio Ambiente da Prefeitura Municipal de São José dos Pinhais. O enfoque deve ser dado aos alunos dos ensinos fundamental e médio, muito embora deva ser efetivada também a outros grupos, tais como empregados e empregadores, bem como a comunidade local, por meio de suas associações de moradores.

6. Aplicação da Lei Estadual $n^{\circ} 13.448$, de 11 de janeiro de 2002, que regulamenta as auditorias ambientais compulsórias nas indústrias potencialmente poluidoras e outras atividades de interesse ambiental.

7. Estabelecer um programa de controle da qualidade hídrica do Rio Arujá mediante a realização de análises físico-químicas e microbiológicas das águas conforme preconizado na Resolução CONAMA n 357/2005.

Todas essas medidas visam uma maior proteção do recurso, mas elas não se encerram em si: outras medidas podem ser adotadas, sempre em cumprimento da legislação ambiental vigente e com o intuito de minimizar todo e qualquer impacto que possa trazer prejuízos ao recur- 
so hídrico. Cabe salientar, no entanto, que dentre todas as medidas que podem ser adotadas, a que diz respeito à educação ambiental, com a formação de uma consciência verdadeiramente ecológica, é a que mais efeitos pode produzir, uma vez que todas as outras ações só podem surgir a partir de uma mente sadia e preocupada com a integridade do meio físico onde ela própria ocupa um espaço ao longo do tempo.

Com a recente adoção do PNRH - Plano Nacional de Recursos Hídricos - o Brasil dá um grande salto para a preservação do recurso natural "água" e se consolida como uma nação soberana nesse aspecto. De acordo com a ONU, que estipulou o ano de 2005 para que os países-membros elaborassem seus planos de gestão integrada de recursos hídricos, o Brasil é um dos poucos países do mundo, o único da América Latina, que está cumprindo essa meta do milênio. Se for considerado que um dos programas prioritários previstos no plano é o de educação ambiental, esse é um programa que vai ter um grande efeito junto à sociedade.

Vê-se, portanto, que todas as ações de proteção ambiental acabam voltando-se para a questão fundamental: a educação ambiental. Sem ela praticamente todas as ações ambientais acabam no ostracismo ilógico e inerte.

\section{Conclusões}

A bacia hidrográfica do Rio Arujá, como a grande maioria das bacias presentes no território nacional, sofre uma série de agressões ambientais conhecidas de longa data. Desde que o homem iniciou sua convivência com a natureza e procurou seu contato direto com a água, essas agressões tiveram início.

Ainda que a legislação ambiental brasileira seja um exemplo para outras nações do mundo, a falta do seu cumprimento e a impunidade àqueles que displicentemente destroem os recursos naturais são os fatos mais evidentes nessa questão, conforme já afirmado por Cruz (2005).

Apesar das agressões serem evidentes, de muitas delas provocarem efeitos diretos sobre a biota e afetar todos aqueles que vivem das águas desse rio, e ainda, ser esse recurso hídrico freqüentemente alvo de manchetes nos meios de comunicação, a população, em sua maioria, e as autoridades constituídas têm-se mostrado pouco sensibilizadas para a defesa desse recurso natural.

A água, molécula propiciadora da vida em nosso planeta, substância fundamental para uma quantidade quase infinita de reações químicas nos meios intra e extracelulares, parece ser o alvo incessante e pecaminoso de uma massa ignorante e sem formação.

A questão da educação ambiental deve ser salientada neste contexto. Ela deve ser conduzida de forma definitiva e consistente pelos educadores e pais, direcionando-a aos jovens, visando ressaltar a real necessidade de proteger esse recurso natural vital. A Lei Municipal $n^{\circ} 45$, de 31 de julho de 1995, que criara a Área de Proteção Ambiental - APA - do Arujá e revogada pela Lei Municipal n65, de 12 de dezembro de 1997, indubitavelmente contribuiria para a preservação da bacia desse rio tão importante para o abastecimento de água da Região Metropolitana de Curitiba. Tal ato representou um retrocesso no processo de proteção ambiental da bacia do rio Arujá, restando apenas a aplicação das legislações mais amplas, a nível estadual e federal.

\section{Referências}

ANDREOLI, C. V. Mananciais de abastecimento: planejamento e gestão. Estudo de caso do Altíssimo Iguaçu. Curitiba: SANEPAR Finep, 2003.

BRASIL, Lei Federal n 4.771, de 15 de setembro de 1965. Institui o novo Código Florestal. Diário Oficial da União, de 28 de setembro de 1965. Brasília, DF.

CONAMA - CONSELHO NACIONAL DO MEIO AMBIENTE. Resolução n 357 , de 17 de março de 2005. Dispõe sobre a classificação dos corpos d'água e diretrizes ambientais para o seu enquadramento, bem como estabelece as condições e padrões de lançamento de efluentes, e dá outras providências. Diário Oficial da União, de 18 mar. 2005. Brasília, DF.

IBGE - Censo demográfico de 2000. Disponível em: <http://www.ibge.gov.br/>. Acesso em: 20 dez. 2005.

IBGE - Solos do Brasil, 2001. Disponível em:

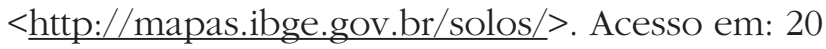
de out. 2005. 
IDU - Instituto de Desenvolvimento Urbano. Prefeitura Municipal de São José dos Pinhais.

Mapeamento de Satélite de Alta Resolução Quickbird II. Resolução espacial 0,60 m / Resolução Radiométrica 4 Bandas Espectrais. Projeção: UTM Zona 22 SUL. Datum: SAD-69/Brasil 06 de jul. de 2004.

IDU - Instituto de Desenvolvimento Urbano. Prefeitura Municipal de São José dos Pinhais. Lei Complementar n. ${ }^{\circ} 16$ de 11 de novembro de 2005. Dispõe sobre o Zoneamento, o Uso e a Ocupação do Solo e Sistema Viário do Município de São José dos Pinhais, Estado do Paraná. Jornal São José dos Pinhais Metrópole, n. 1093, de 18 nov. 2005.

PARANÁ, Lei Estadual n. ${ }^{\circ} 12.726$, de 26 de novembro de 1999. Institui a Política Estadual de Recursos Hídricos e adota outras providências. Diário Oficial do Paraná, n. 5. 628, de 29 de novembro de 1999. Curitiba.
PARANÁ, Lei Estadual n. ${ }^{\circ} 13.448$, de 11 de janeiro de 2002. Dispõe sobre a realização de Auditorias Ambientais Compulsórias no Estado do Paraná. Diário Oficial do Paraná, n. 6.148, de 14 jan. 2002. Curitiba.

SÃO JOSÉ DOS PINHAIS - PR. Prefeitura Municipal, Lei n. ${ }^{\circ} 45$ de 31 de julho de 1995.

SÃO JOSÉ DOS PINHAIS - PR. Prefeitura Municipal, Lei n. ${ }^{\circ} 65$ de 12 de dezembro de 1997.

SÃO JOSÉ DOS PINHAIS - PR. Prefeitura Municipal, Lei n. ${ }^{\circ} 175$ de 14 de maio de 2001.

SICTUR - Secretaria da Indústria, Comércio e Turismo do Município de São José dos Pinhais. Catálogo das Indústrias 2004 - São José dos Pinhais. Curitiba: NETMídia Computação Gráfica Ltda., 2004. 1 CD-ROM. 